\title{
De la teología a la identidad en la arquitectura religiosa contemporánea
}

\author{
From theology to identity in contemporary religious architecture
}

Rafael Ángel García Lozano

https://doi.org/10.17979/aarc.2011.2.2.5050

\section{INTRODUCCIÓN}

Es evidente que el templo actual, al igual que el generado a lo largo de las distintas épocas de la historia, ha de dar respuesta al hombre concreto al que trata de servir, a su vivencia de la fe y a su expresión de la comunión con Dios y los hombres. Centrándonos en la época contemporánea, el templo queda determinado a partir de unas concepciones y categorías teológicas específicas que lo fundamentan. Por ello, es necesario trazar una explicitación, reflexión y puesta en relación de distintos aspectos que se desprenden del análisis y estudio de lo que se constituye como la identidad de la arquitectura religiosa contemporánea a partir de los principios teológicos que están tras ella y que la fundamentan.

\section{LA ARQUITECTURA RELIGIOSA, LUGAR TEOLÓGICO}

El templo católico, y en concreto el templo contemporáneo, existe por y para una comunidad de cristianos. Ello implica la consideración de esta arquitectura como lugar teológico, pues existe y se expresa a la vez desde un doble fundamento cristológico y eclesiológico, mutuamente implicados, en virtud de Cristo y su cuerpo, que es la Iglesia. Esto supone que el templo católico existe porque la Iglesia (eclesiología) se reúne para celebrar los misterios de Cristo (cristología). Por tanto, podemos afirmar la existencia de dos realidades teológi- cas que fundamentan el ser de esta arquitectura: la cristológica y la eclesiológica.

Cuando esta fundamentación se lleva a efecto podemos considerar que la arquitectura religiosa se hace ámbito donde se manifiesta por medio de la teología la concepción del hombre y la Iglesia, así como la forma de entender a Dios. Hablamos, pues, de un verdadero acompasamiento existente entre la teología y la arquitectura religiosa, realidad que no siempre ha sido así. De hecho sabemos que, o por falta de libertad de los artistas $\mathrm{y}$ arquitectos o por incapacidad de la Iglesia de responder a su tiempo, han sido varios los momentos en que no han ido de la mano la teología y sus representaciones artísticas. Por ello es necesario afirmar que ambas disciplinas necesitan interrelacionarse de tal modo que se produzca una efectiva complementariedad entre ellas.

Pues bien, esta afirmación de la necesaria fundamentación teológica de las realizaciones artísticas, y en concreto arquitectónicas, nos lleva a exponer la doble fundamentación teológica de la arquitectura religiosa contemporánea en la cristología y la eclesiología.

\section{FUNDAMENTACIÓN CRISTOLÓGICA}

El Dios cristiano es un Dios Padre, Hijo y Espíritu Santo. Es Dios Uno y Trino, revelado en Jesucristo como Dios personal y misterio de comunión. La esencia de Dios es, pues, comunión por la que el Padre genera en el amor al Hijo, y con el Hijo tiene lugar la entrega 
del Espíritu Santo. Desde esta ontología comunional, el hombre está llamado a la comunión perfecta con su creador, del mismo modo que también lo está la Iglesia, esencialmente misterio de comunión de los hombres con y por Jesucristo en virtud del Espíritu Santo ${ }^{1}$.

El acceso de la Iglesia, de los hombres, al ser de Dios viene dado por la autorevelación de Dios al hombre por medio de Jesucristo. Dios se dice de sí mismo y se manifiesta. Desde esta clave, también Dios se manifiesta en la belleza que los hombres crean como reflejo y participación en la belleza de lo creado por Dios. Por eso el teólogo Hans Urs von Balthasar, reclamando la belleza como una de las más excelsas formas de revelación de Dios, ha señalado que éste se revela en una belleza que es igualmente Bien y Verdad, que es gloria de Dios en Cristo. De ahí se sigue entonces que podemos aseverar que Cristo es la 'obra de arte' central de Dios$^{2}$.

La arquitectura religiosa contemporánea no es ajena a la belleza, más aún, está vocacionada a ser ámbito de la belleza de Dios. Como ya hemos apuntado, los templos a lo largo de la historia, también los contemporáneos, se han dispuesto como la «conjunción del espacio de los hombres y el espacio de la divinidad, el espacio del cielo y el de la tierra. Y en el caso del cristianismo, esa conjunción ha sido precisamente Jesucristo, que es ese umbral donde el hombre empieza a ser Dios y Dios empieza a ser hombre. El templo quiere ser precisamente la representación espacial de Jesucristo, siendo hombre y Dios a la vez» ${ }^{3}$.

Pues bien, para los cristianos el verdadero templo de Dios no es espacial, sino personal: Jesucristo, Hijo de Dios. Por razón de su humanidad y su corporalidad él es el verdadero templo de Dios. Adorándolo a él se adora a Dios. Su cuerpo es el definitivo lugar de la adoración, por lo que el templo de Jerusalén quedó derogado 4 . Ahora podemos entender el pasaje evangélico de Juan (cf. Jn 2, 14-22), donde el propio texto aclara en el versículo 21: «Pero él se refería al templo de su cuerpo». Las palabras de Jesús sólo fueron comprendidas más tarde, a la luz de su resurrección, cuando sus discípulos entendieron que el nuevo y verdadero templo del nuevo pueblo de Dios es Jesús mismo en virtud de su humanidad, más en concreto, de su corporalidad5.

El horizonte de sentido de la religión judía era en tiempos de Jesús, y sigue siendo aun hoy, un solo Dios, un solo pueblo de Dios, un solo lugar de su presencia.
Pero con Jesucristo «el templo de Jerusalén debía dejar paso al templo nuevo, ya que no es un lugar físico, un edificio siquiera agraciado con una peculiar presencia de Dios, sino un Hombre, más exactamente, la humanidad del Dios hecho hombre, el Hombre Cristo Jesús ${ }^{6}{ }$. La sustitución del templo de Jerusalén por el mismo Jesucristo no es un desprecio hacia el templo, sino una superación de éste ${ }^{7}$. En los planes de Dios es la humanidad misma de la persona del Verbo quien es el nuevo templo de Dios. Y ello es posible gracias al misterio de la encarnación. Como se dice en el prólogo del evangelio según San Juan (cf. Jn 1, 14), Cristo acampó entre nosotros, plantó su tienda en medio de los hombres. Esta imagen tomada de la experiencia del pueblo de Dios en el desierto en su continuo plantar y recoger la tienda es elocuente para la comprensión del templo contemporáneo ${ }^{8}$. Dios viene a morar entre los hombres y para ello envía a su Hijo a vivir la misma vida de los hombres. Así pues, Dios no entra en la historia humana de forma espiritualista, sino desde la totalidad humana, desde la parte más tangible, su propia corporalidad, hecho verdadero hombre. El Verbo hecho hombre, Jesús, se identificó con la morada definitiva de Dios entre los hombres9.

\section{FUNDAMENTACIÓN ECLESIOLÓGICA}

Una vez que nos hemos centrado en el estudio de Cristo como el verdadero templo de Dios, pasamos ahora a analizar el templo que formamos todos los cristianos. En la primera carta de Pablo a los Corintios, el apóstol escribe (1 Cor 3, 16): «sois edificio de Dios». En este texto Cristo aparece como el fundamento, el cimiento del edificio, y sobre él se va levantando la construcción, formada por piedras vivas. Así pues, el edificio tiene su cimiento en Cristo y sobre él se elevan los cristianos. De igual modo se ha narrado en 1 Cor 3 , 9-11. Otro tanto ocurre en 1 Pe 2, 4-5, donde Pedro es el arquitecto del nuevo pueblo de Dios edificado en la historia humana. En 2 Cor 6, 16, se repite la idea de que somos los cristianos el templo de Dios vivo.

Si en el apartado anterior sosteníamos que el cuerpo de Jesús era el templo de Dios, en este, en cambio, afirmamos que el templo sigue siendo ese mismo cuerpo de Jesús, pero ahora ese cuerpo de Cristo somos los cristianos. El salto de una a otra afirmación viene dado por Jn 12, 32: «Cuando yo sea levantado sobre la tierra, atraeré a todos los hombres hacia mí». El cuerpo exaltado y glorioso de Cristo tiene una potencia atractiva, una 
capacidad de imantar la humanidad hacia Dios transformándola en su cuerpo. La salvación otorgada por Cristo transforma al bautizado de forma que pasa a ser Iglesia, es decir, cuerpo de Cristo ${ }^{10}$. El ser y vivir como cristianos hace de los hombres el verdadero templo de Dios.

Según esto el templo de Dios no está vinculado a un lugar, sino que está en todas partes, donde quiera que estén los cristianos, y el culto que Dios busca es el culto en Espíritu y verdad. Muestra de ello es el texto evangélico de la Samaritana (cf. Jn 4, 19-24), donde Jesús mismo pide la adoración a Dios en Espíritu y verdad. Y esta adoración no puede quedar encerrada en un lugar, sino que ha de darse en todas partes. Verdaderamente el templo está en todas partes porque Cristo, que es el verdadero Templo, nos hace miembros de su Cuerpo y nos hace participar de su propia adoración, de modo que nosotros adoramos al Padre con él.

$\mathrm{Si}$ el templo era en las distintas religiones, y de modo eminente en la religión judía, lugar de la presencia de Dios y de la adoración de los hombres, en el Nuevo Testamento el lugar de adoración a Dios es una persona, Jesucristo. Pero el templo somos también todos los cristianos, pues somos asumidos por Cristo haciéndonos miembros de su Cuerpo, constituyendo la Iglesia. De este modo cada acontecimiento de la historia es lugar para la adoración a Dios. El templo está, entonces, en todas partes.

Sentadas estas bases, podemos ahora entrar a desbrozar el terreno de los templos contemporáneos, pues, como vimos más arriba, mientras la Iglesia peregrina en la historia construye lugares para la reunión comunitaria y para la celebración de los misterios de la fe. No por esto queda invalidada la afirmación de que el templo está en todas partes sino que, precisamente por ello, la Iglesia ha necesitado siempre dotarse de ámbitos para ello. Son necesarios edificios sagrados visibles, que sean signos peculiares de la Iglesia peregrina en la tierra e imagen terrestre de la Jerusalén del cielo. Y porque se construyen como edificios destinados de manera fija y exclusiva a reunir al pueblo de Dios para celebrar los sagrados misterios se ha juzgado conveniente dedicarlos al Señor. En forma muy especial el templo católico es el lugar donde la comunidad puede encontrar a Dios, el lugar donde la Iglesia crece como cuerpo místico y por lo cual el templo es símbolo significativo de ese cuerpo de Cristo, donde se anticipa la unión de Dios con su pueblo hasta el final de los tiempos. Sólo en la Iglesia consumada en la escatología el templo será Cristo mismo ${ }^{11}$. Al construir un templo hay que tener en cuenta todas estos elementos a fin de que resulte un edificio verdaderamente bello, significativo y sobrenaturalmente funcional ${ }^{12}$.

\section{APROXIMACIÓN A LA IDENTIDAD DE LA ARQUITECTURA RELIGIOSA CONTEMPORÁNEA}

La especificidad de la arquitectura religiosa contemporánea estriba en las características concretas con las que la época contemporánea ha caracterizado esta arquitectura. Ciertamente, la impronta de los tiempos, junto con las distintas concepciones teológicas, son los ámbitos lo que determinan las diversas concepciones de arquitectura litúrgica.

Ahora bien, también son determinantes otros elementos además de los factores temporal y teológico a la hora de hablar específicamente de la arquitectura religiosa contemporánea. Destacamos, entre otros muchos, la autoconcepción antropológica personal, el sentido comunitario de la asamblea y el grado de relacionalidad intersubjetiva, la capacidad referencial e icónica de la iglesia respecto de la parroquia, su ubicación contextual en el medio, la mera materialidad del templo, la coyuntura socioeconómica disponible a la hora de la construcción, la propia comprensión de la arquitectura, la tensión funcionalidad-simbolismo del templo, la forma arquitectónica de expresión en determinadas formas y volúmenes, etc. La conjugación de todos estos elementos, por otro lado universales en todas las épocas, da como resultado una determinada tipología arquitectónica religiosa.

Pero no cabe duda de que los factores más determinantes que han desencadenado la aparición y consolidación de la tipología religiosa contemporánea son principalmente la evolución arquitectónica y la renovación teológica, que además de originarse prácticamente a la vez, se han ido desarrollando paralelamente y han influido constantemente una sobre la otra.

$\mathrm{Si}$ atendemos al desarrollo experimentado por la arquitectura en el siglo XX podemos constatar la aparición de una nueva mentalidad más racional, la experimentación y el logro de nuevos materiales más versátiles y con mayores posibilidades constructivas, además de la

(En página siguiente) Heinz Tesar, Cristo Salvador del Mundo, Donnau City (Austria), 1998-2000 


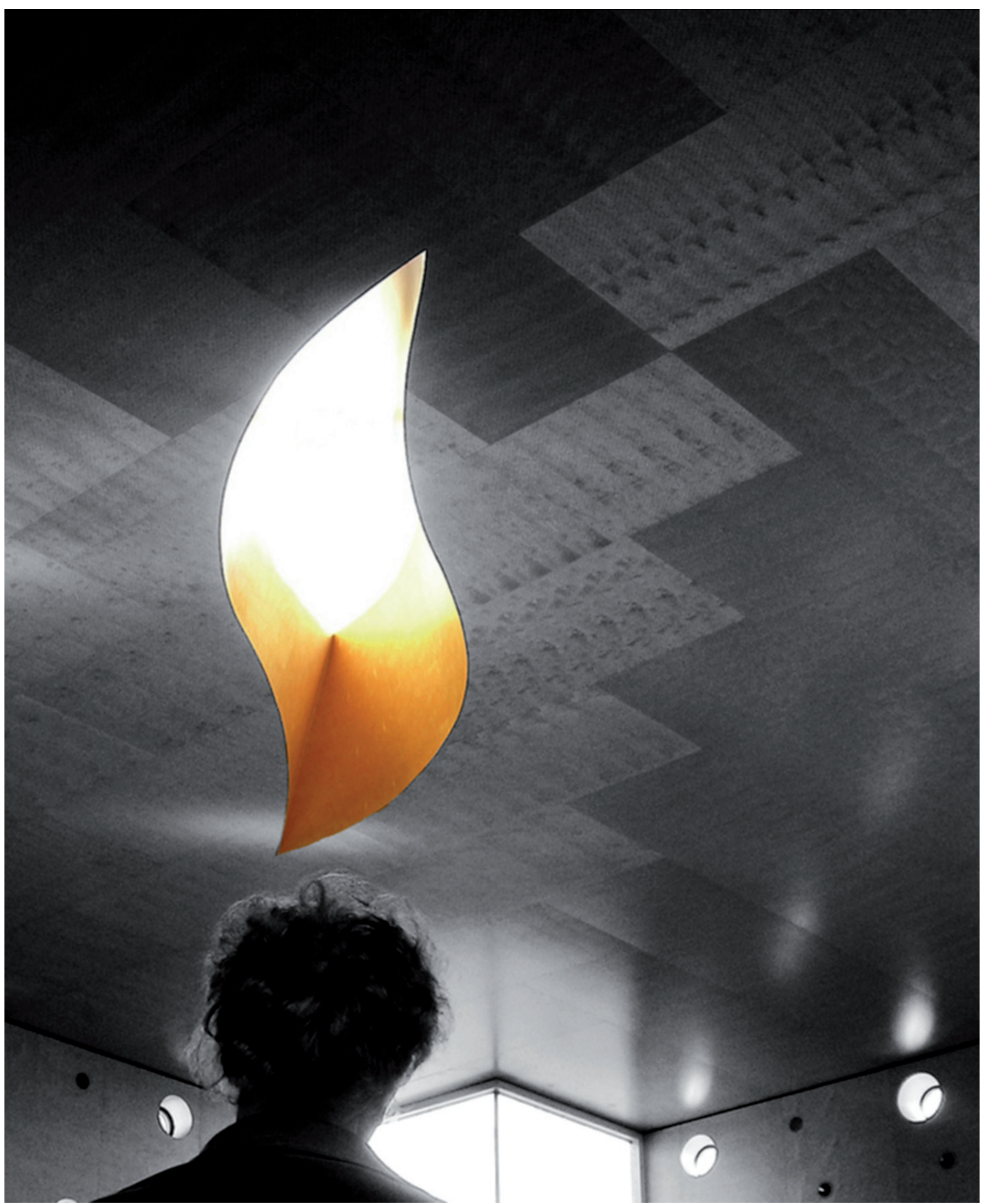


decisiva influencia de las tendencias centroeuropeas. Todo ello coincidió en nuestro país con una generación de jóvenes arquitectos rupturistas con la tradición y educación recibidas que, vista la inviabilidad del monumentalismo y casticismo franquista al uso, se entregaron de lleno a la asunción de estas nuevas corrientes. Una nueva proyección bajo un programa ordenado y una reestructuración adecuada de los espacios se alió con el recurso a la sugerencia y los principios racionales de la sencillez y sinceridad de materiales y formas. Enseguida se extendió por todo el panorama arquitectónico y comenzó a llevarse a la práctica la famosa sentencia de Mies van der Rohe 'menos es más'. Esta apuesta por la esencialización arquitectónica y por la autenticidad formal encajó perfectamente con las concreciones desprendidas de la renovación del pensamiento teológico.

En efecto, se produjo un florecimiento de la patrística, los estudios bíblicos resurgieron con fuerza, el movimiento litúrgico renovador se fue afianzando sobre bases realmente teológicas y se iba favoreciendo una verdadera espiritualidad cristocéntrica ${ }^{13}$. Pero todo ello son concreciones de ese fenómeno de renovación teológica que fue verdaderamente nuclear. De él se seguía fundamentalmente una nueva eclesiología. De un planteamiento eclesiocéntrico fuertemente societario se pasaba a un planteamiento en el que la Iglesia se descubre en su profunda raíz mistérica, entroncada en el designio salvífico de Dios. La igualdad fundamental de todos los cristianos en virtud del bautismo y su llamada a la santidad hacían de las categorías Pueblo de Dios y Comunión una alternativa eclesiológica profunda. La colegialidad episcopal, la importancia de las iglesias locales y la centralidad de la escatología alumbraban nuevas expectativas para los cristianos ${ }^{14}$.

De estas claves teológicas se siguieron determinadas concreciones para la nueva arquitectura religiosa ${ }^{15}$. La centralidad de Cristo como fundamento teológico de la arquitectura religiosa contemporánea tiene su más elocuente concreción en la planta centralizada ${ }^{16}$, mejor aún, en la centralidad del altar. Ya Johannes van Acken desarrolló en su discurso teológico a comienzos del siglo XX la importancia preponderante de Cristo en el templo, reflejado a su entender de forma suprema en la planta centralizada ${ }^{17}$. La disposición circular de los fieles en torno al altar subraya de forma magistral el cristocentrismo del que hablamos. No sólo se trata de construir la planta del templo con forma circular, sino que la clave está en la disposición concéntrica de los fieles, focalizando sus miradas en el altar y en los otros focos litúrgicos, ambón y sede. La fundamentación cristológica queda así puesta de relieve en la arquitectura religiosa.

Del mismo modo era necesario mostrar también arquitectónicamente la ministerialidad de los cristianos. El templo se distribuye según espacios propios, concretándose de la jerarquización de espacios y teniendo como objetivo fundamental la participación de toda la asamblea. De inmediato se apuesta por la funcionalidad litúrgica del templo, sin olvidar tampoco la importancia del simbolismo. La belleza no está reñida con la sobriedad ni con la sencillez en la comprensión del espacio y orden, sino que, más bien, éstos la hacen posible ${ }^{18}$. Nobleza, decoro, simplicidad, veracidad y autenticidad se complementarán con la estética para hacer posible el recurso a la sugerencia como principio artístico princi$\mathrm{pal}^{19}$. «La expresión de unos valores espirituales religiosos (...) no puede ser compleja, y (...) el lenguaje que ha de utilizar el arquitecto ha de estar basado, en lo fundamental, en aquellas formas necesarias para servir a dichas funciones» ${ }^{20}$.

A partir de estos principios, a mediados del pasado siglo se buscaron y se lograron los medios para que los fieles participaran en el misterio y en la vivencia de espacios sensibles y bellos que, desde la sobriedad, elegancia y belleza, posibilitaran sentir al Dios trinitario. Así se despejó la duda tan ampliamente manifestada de si la nueva arquitectura respondía y aún hoy responde a las necesidades del momento ${ }^{21}$. La pregunta recurrente por si eran profanas o protestantes las nuevas iglesias 22 ponía de manifiesto la duda ante nuevas formas, que no se sabía qué traerían tras de sí23. Miguel Fisac reconoció que determinadas tendencias de arquitectura religiosa respondían a diversas concepciones de la realidad religiosa, aventurándose a ofrecer la que él entendía más adecuada. Según este arquitecto hay una posición que consiste «en restaurar el sentido sobrenatural de la vida cristiana con la visión de nuestro sentido actual de la vida. Es una consecuencia de releer el evangelio, de releer la liturgia (...). Al expresar arquitectónicamente esta posición, que no es estética, sino religiosa, profunda y auténticamente religiosa, surge entonces una arquitectura totalmente distinta: ni antigua ni moderna, sino nueva, en el que una iglesia no es un lugar con un retablo y con unos altares, sino que es un espacio en donde se reúnen los fieles para la oración, para la celebración 
de la santa misa, para la adoración eucarística (...). Una iglesia concebida así exige una piedad, no sólo una acomodación estética» ${ }^{24}$. Fisac termina afirmando que las iglesias contemporáneas deben preocuparse por ser limpias y sencillas para que acerquen a Dios. Y esto o se hace realmente efectivo o simplemente queda en meros intentos irrealizados.

La consideración de las distintas realizaciones de arquitectura religiosa contemporánea creadas en los últimos cincuenta años acaban dando razón efectiva de que tanto su concepción como espacio litúrgico cuanto su materialidad como edificios contemporáneos están radicados en una efectiva cuestión sociológica, artística, histórica incluso y, por supuesto, arquitectónica, pero fundamentalmente asentados sobre una base teológica que las fundamenta radicalmente y constituye su identidad.

\section{NOTAS}

(1) Cf. Concilio Vaticano II, Decreto «Unitatis Redintegratio» sobre el ecumenismo, $\mathrm{n}^{\circ} 2$.

(2) Cf. Hans Urs von Balthasar, «Verbum Caro», Cristiandad, Madrid, 2001; pág. 103-135. En esta misma línea véase Maria Antonietta Crippa, «Renovação do concilio Vaticano II, suas consequências para arquitectura e para a arte», en VVAA, «Novas igrejas de vàrios tempos», Rey dos Livros, Lisboa, 1998; pág. 33.

(3) Jesús María Aparicio Guisado, «Iglesia en Andalucía»; conferencia pronunciada dentro del ciclo organizado por la Fundación Félix Granda «La arquitectura sacra en el siglo XXI. Diálogo-creaciónfinalidad» (Alcalá de Henares, 15-17 de noviembre de 2001); inédita.

(4) Cf. Yves-Maria Congar, «El misterio del templo», Estela, Barcelona, 1967; pág. 156-162.

(5) Cf. Ibídem; pág. 162-174.

(6) Pedro Rodríguez García, «¿Qué es propiamente un templo católico», en VVAA, «Templo cristiano y espacio litúrgico», Fundación Félix Granda, Madrid, 2003; pág. 23.

(7) No hay desprecio de Jesús hacia el templo. Lo vemos en Lc 2, 40-52, donde se nos relata el pasaje donde él mismo se quedó en el templo escuchando a los maestros de la ley, o cuando Él mismo dice del templo «la casa de mi Padre» o se afirma «mi casa es casa de oración» en Mt 21, 13.

(8) Cf. Pedro Rodríguez García, «QQué es propiamente un templo católico», cit.; pág. 25.

(9) Cf. CIC $\$ 586$.

(10) Cf. Pedro Rodríguez García, «¿Qué es propiamente un templo católico», cit.; pág. 28 .

(11) Cf. Yves-Maria Congar, «El misterio del templo», cit.; pág. 254.

(12) Cf. Angel Sancho Campo, «Editorial», Ars Sacra 7 (1998), pág. 3.

(13) Cf. Eloy Bueno de la Fuente, «Eclesiología», BAC, Madrid, 1998; pág. 15.

(14) Ibídem; pág. 16.

(15) Conviene poner de relieve esta profunda y necesaria vinculación que debe existir entre ambas realidades. No cabe duda de que una buena teología aplicada está en disposición de dar lugar a una buena arquitectura religiosa, como hemos visto. Por ello podemos afirmar que ciertas desvinculaciones entre ambas se traduce en «la falta de una cultura moderna de la religión católica; hasta que ésta no se diese no existiría ni en el pueblo ni en el clero el deseo de una nueva y verdadera arquitec- tura religiosa» (Esteban Fernández Cobián, «Redescubriendo el templo», Arquitectos 163 (2002), pág. 51).

(16) Paloma Gil Giménez trata ampliamente el tema del templo cristocéntrico en Dominikus Böhm en su libro «El templo del siglo XX» (Ediciones del Serbal, Barcelona 1999). También estudia con profundidad las variaciones del espacio central, así como alternativas en la direccionalidad axial en los templos contemporáneos (cf. pág. 74-80, 85-91 y 120125).

(17) Cf. Johannes Van Acken, «Christozentrische Kirchenkunst. Ein Entwurf zum liturgischen Gesamtkunstwerk», Theben, Gladbeck 1923.

(18) A este respecto, el arquitecto Javier Carvajal Ferrer se expresa de la siguiente forma: «Frente al espectáculo agobiante del consumo, de la riqueza insultante y del dinero que se nos ofrece como único valor supuestamente aceptado, los cristianos, en nuestra arquitectura y nuestro arte, debemos procesar la sobriedad y la sencillez, que no está reñida con la belleza que el hombre necesita, como lo prueba su abrumadora presencia en la obra de Dios que tiene como único destinatario al hombre» (Eduardo Delgado Orusco, «Porque vivir es difícil. Conversaciones con Javier Carvajal Ferrer», Universidad Camilo José Cela, Madrid, 2002; pág. 79)

(19) «Hay una simplicidad que es expresión de madurez (...) La tensión más alta del espíritu, la más alta purificación, la más alta madurez generan la simplicidad auténtica» (Joseph Ratzinger, «La festa della fede», Jaca Book, Milán, 1983; pág. 98). Véase también una aplicación de esto mismo en Josep Maria Masramón de Ventós, «Art litúrgic», en VVAA, «Art Sacré», Diputación Provincial de Gerona y COACB, Girona, 1965; pág. 58-67.

(20) Gerardo Cuadra Rodríguez, «La experiencia de la Liturgia en el artista», en José María Fernández Catón (coord.), «Arte Sacro y Concilio Vaticano II» (Ponencias y comunicaciones de la II Semana Nacional de Arte Sacro), Junta Nacional Asesora de Arte Sacro y Centro de Estudios e Investigación San Isidoro, León, 1965; pág. 392.

(21) A esta cuestión responde Javier Carvajal en los siguientes términos: «No vuelvan a decir, delante de mí, que el arte moderno no sirve para ser ofrecido a Dios, (...) [que] no sirve para expresar el encuentro de nuestro tiempo, a través de la emoción, con el Señor de los tiempos (...) porque esto ni es inteligente, ni es verdadero, ni es cristiano» (Eduardo Delgado Orusco, «Porque vivir es difícil», cit.; pág. 71-72). Él mismo afirma también que sólo la arquitectura sacra contemporánea puede comunicar el misterio si no se olvida de la voluntad de servicio al destinatario de la arquitectura, el hombre. Cf. Ignacio Vicens Hualde y Rafael Llano Sánchez, «La arquitectura debe recuperar el misterio», Nueva Revista 58 (1998), pág. 19. Véase también el «Editorial» correspondiente a Arquitectura 147 (1971), pág. 1.

(22) Esta cuestión viene recogida expresamente y contestada por dos de los principales estudiosos de este tema desde la reflexión teórica de la práctica, a saber: Arsenio Fernandez Arenas, «Iglesias nuevas en España», La Polígrafa, Barcelona, 1963; pág. 103-105 y Juan Plazaola Artola, «El arte sacro actual», BAC, Madrid, 1965; pág. 284-289.

(23) Las nuevas inquietudes como el afán de comunidad, el deseo de verdad y autenticidad, el paso de lo superficial a lo esencial, la nostalgia de silencio y de paz, etc., ponían de relieve los nuevos principios de los que ya nos hacemos eco. Cf. Comisión Litúrgica de la Conferencia Episcopal de Fulda-Alemania, «Directrices para la construcción de iglesias según el espíritu de la Liturgia Romana», en Juan Plazaola Artola, «El arte sacro actual», cit.; pág. 570 y 298. Véanse también los argumentos expuestos por José Manuel de Aguilar Otermín, «Esquema de una conferencia en el ciclo de arte sacro palabra-altar-eucaristía-penitencia», en VVAA, «Art Sacré», Diputación Provincial de Gerona y COACB, Gerona, 1965; pág. 46-56.

(24) Miguel Fisac Serna, «El futuro de la arquitectura religiosa», Seminarios 16 (1962), pág. 102. 